CONCISE REPORT

\title{
Tumour necrosis factor $\alpha$ blockade in treatment resistant pigmented villonodular synovitis
}

\author{
E-J A Kroot, M C Kraan, T J M Smeets, M Maas, P P Tak, J M G W Wouters
}

Ann Rheum Dis 2005;64:497-499. doi: 10.1136/ard.2004.025692

\begin{abstract}
Background: Pigmented villonodular synovitis (PVNS) is considered to be a neoplastic-like disorder of the synovium histologically characterised by villonodular hyperplasia, resulting in dense fibrosis and haemosiderin deposition. The pathogenesis of the disease is still unknown.

Case report: A patient presented with severe treatment resistant PVNS of the right knee joint. Several conventional treatment regimens, including open surgical synovectomy and intra-articular injections of yttrium-90 $\left({ }^{90} \mathrm{Y}\right)$ failed to control the disease. After finding marked tumour necrosis factor $\alpha(\mathrm{TNF} \alpha)$ expression in arthroscopic synovial tissue samples, treatment with an anti-TNF $\alpha$ monoclonal antibody (infliximab) at a dose of $5 \mathrm{mg} / \mathrm{kg}$ was started. Additional courses with the same dose given 2, 6, 14, and 20 weeks later, and bimonthly thereafter up to 54 weeks, controlled the signs and symptoms. Immunohistological analysis at follow up identified a marked reduction in macrophage numbers and TNF $\alpha$ expression in the synovium.

Discussion: This is probably the first case which describes treatment with TNF $\alpha$ blockade of PVNS in a patient who is refractory to conventional treatment. It provides the rationale for larger controlled studies to elucidate further the efficacy of TNF $\alpha$ blockade treatment in refractory PVNS.
\end{abstract}

l: 1941 Jaffe et al described pigmented villonodular synovitis (PVNS) as an inflammatory and reactive disease of synovial tissues caused by uncertain trauma of the joint. ${ }^{1}$ Since then, localised and diffuse forms of synovial disease have been reported..$^{2-5}$ In general, the disease is considered to be a premalignant disease because of its effects on joint structures and integrity, although its exact cause remains unknown..$^{2-5}$ The most commonly affected site is the knee, but it can be present in any synovial joint. PVNS is a rare disease with an annual incidence of 1.8 and a prevalence of 9.2 patients per million population. ${ }^{2}{ }^{6}$ Untreated it can result in severe joint damage with accompanying disability. Therefore, PVNS is treated aggressively; the preferred treatment is surgical synovectomy (either arthroscopically or open), eventually followed by radiosynovectomy with intra-articular injection of yttrium-90 $\left({ }^{90} \mathrm{Y}\right) \cdot{ }^{3}$ Nevertheless, the disease may reoccur after these treatments. A recurrence rate of between 25 and $45 \%$ has been reported. ${ }^{3}$

Recently, the presence of macrophages and related proinflammatory cytokines such as tumour necrosis factor (TNF) $\alpha$ has been described in PVNS. ${ }^{78}$ These findings offer new insights into the pathomechanism of PVNS by suggesting that periarticular bone resorption and cartilage destruction which characterise PVNS may be related to the expression of proinflammatory cytokines, which in turn stimulate matrix metalloproteinase production. As a consequence, TNF $\alpha$ blockade might be a new therapeutic option for stopping, or at least delaying, destruction in refractory PVNS. Currently, no cases of $\mathrm{TNF} \alpha$ targeted treatment have been reported.

\section{CASE REPORT}

In 1994 a 22 year old man, presented with monarthritis of the right knee joint. A diagnosis of the localised form of PVNS was made by arthroscopy and confirmed by histological examination. In 1995 an open surgical synovectomy was performed because of persistent disease. The result of this treatment was unsatisfactory and the disease recurred in 1996. Magnetic resonance imaging (MRI) showed enhanced synovium surrounding the haemosiderin deposits, indicating persistent synovitis located posterior in the knee joint and an intercondylar erosion with a diameter of $1 \mathrm{~cm}$. Treatment with an intra-articular injection of ${ }^{90} \mathrm{Y}$ was performed. The results of this procedure were unsatisfactory, and the patient was re-treated 6 months later with an intra-articular injection of ${ }^{90} \mathrm{Y}$ in 1997. After this second intra-articular injection the disease recurred and was controlled by aspiration of synovial fluid and steroids administered locally

During the following years the disease affected activities of daily life (ADL) in such a way that patient had to stop working as a mechanic and changed to an administrative job. During these years radiological examination including plain radiography, computed tomography, and MRI scanning was performed periodically. MRI scanning performed in 1998 showed progression of the disease posterior in the knee joint, progression of effusion, and the existence of the already described intercondylar erosion with a diameter of still $1 \mathrm{~cm}$.

On MRI scanning at the end of 2002, just before treatment with anti-TNF $\alpha$ was started, progressive damage was seen, characterised by hyperproliferative synovium in the complete knee joint, destruction of the cartilage, increase of the intercondylar erosion up to a diameter of $2 \mathrm{~cm}$, and occurrence of several other small erosions.

Because of this progressive radiological damage, persisting synovitis with effusion $(70-80 \mathrm{ml})$, and progressive limitations in ADL, additional analysis of the local pathology was justified. Therefore an arthroscopy of the knee was performed to provide more insight into the pathogenesis of the disease and to evaluate possible treatment options (fig lA). Subsequently multiple synovial samples were obtained as described previously. ${ }^{9}$ At routine histopathology classical histological features were seen, with pigment depositions and an impressive infiltrate. Immunohistology showed that this infiltrate mainly consisted of CD68+ macrophages (clone EBM11; DAKO, Glostrup, Denmark) with abundant presence of anti-TNF $\alpha$ (IP-300;Genzyme) (fig 2).

In response to these findings and the lack of efficacy of conventional treatment, infliximab (5 mg/kg body weight)

Abbreviations: $A D L$, activities of daily living; MRI, magnetic resonance imaging; PVNS, pigmented villonodular synovitis; RA, rheumatoid arthritis; TNF $\alpha$, tumour necrosis factor $\alpha$ 


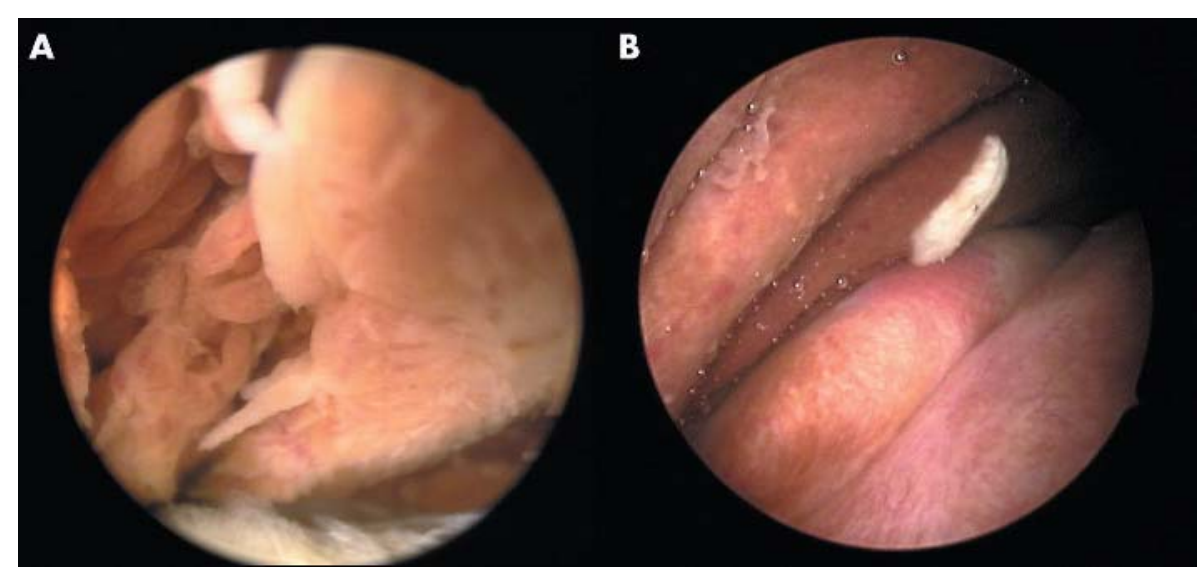

Figure 1 Macroscopic examination of the synovium before (A) and after (B) 20 weeks of treatment with anti-TNF $\alpha$. (A) Hypertrophied synovium with villous transformation and haemosiderin deposition. (B) Reduction of hypertrophied synovium and haemosiderin deposition.

and methotrexate (10 mg/week) was started, which was well tolerated by the patient. Additional courses were administered 2, 6, 14, and 20 weeks later at the same dose; later courses were given at 8 week intervals up to 54 weeks.

During the initial 20 weeks of treatment with anti-TNF $\alpha$ the knee was punctured every 4 weeks for persisting effusion, without instillation of intra-articular corticosteroids. The initial volume was $80 \mathrm{ml}$ and this gradually reduced to $30 \mathrm{ml}$. After the fourth infusion with infliximab at 20 weeks, no synovial fluid could be obtained and the ADL improved considerably. For example, the patient could stand on several consecutive days again without experiencing any pain in the knee joint, which was impossible for him before treatment with infliximab.

To evaluate the histological changes at 20 weeks, a second set of synovial biopsy specimens was obtained by arthroscopy (figs $1 \mathrm{~B}$ and 2 ). A dramatic reduction in cellularity (baseline $1.7 \times 10^{9}$ cells $/$, 20 weeks $0.7 \times 10^{9}$ cells $\left./ 1\right)$, number of macrophages (baseline $1.6 \times 10^{9}$ cells $/ 1 ; 20$ weeks $0.6 \times 10^{9}$ cells $/ 1$ ), estimated pigment (baseline integrated optical density (IOD) $0.6 \times 10^{9} / \mathrm{l} ; 20$ weeks 2.1/1), and TNF $\alpha$ (baseline IOD $236.1 \times 10^{9} /$, 20 weeks $\left.125.5 \times 10^{9} / 1\right)$ was seen.
Based on the response to treatment with infliximab, it was decided to continue treatment with infliximab bimonthly to control local disease activity. MRI scanning performed 10 months after treatment with infliximab showed neither progression nor regression of the synovial tumour mass but also no new or larger erosions in comparison with MRI scanning just before treatment. In conclusion, the patient responded well to this therapeutic regimen with infliximab up to 54 weeks of treatment, without any side effects.

\section{DISCUSSION}

This case is, to our knowledge, the first to demonstrate the efficacy of infliximab treatment in refractory PVNS. After 20 weeks of infliximab treatment marked clinical improvement was seen, and the number of synovial tissue macrophages was considerably reduced.

TNF $\alpha$ blockade was considered as a therapeutic option in our patient with refractory PVNS for several reasons. Firstly, macrophages and related proinflammatory cytokines such as TNF $\alpha$ have been reported to be important in PVNS. ${ }^{7}$ In our case this could be confirmed. Secondly, it has been demonstrated that in patients with rheumatoid arthritis

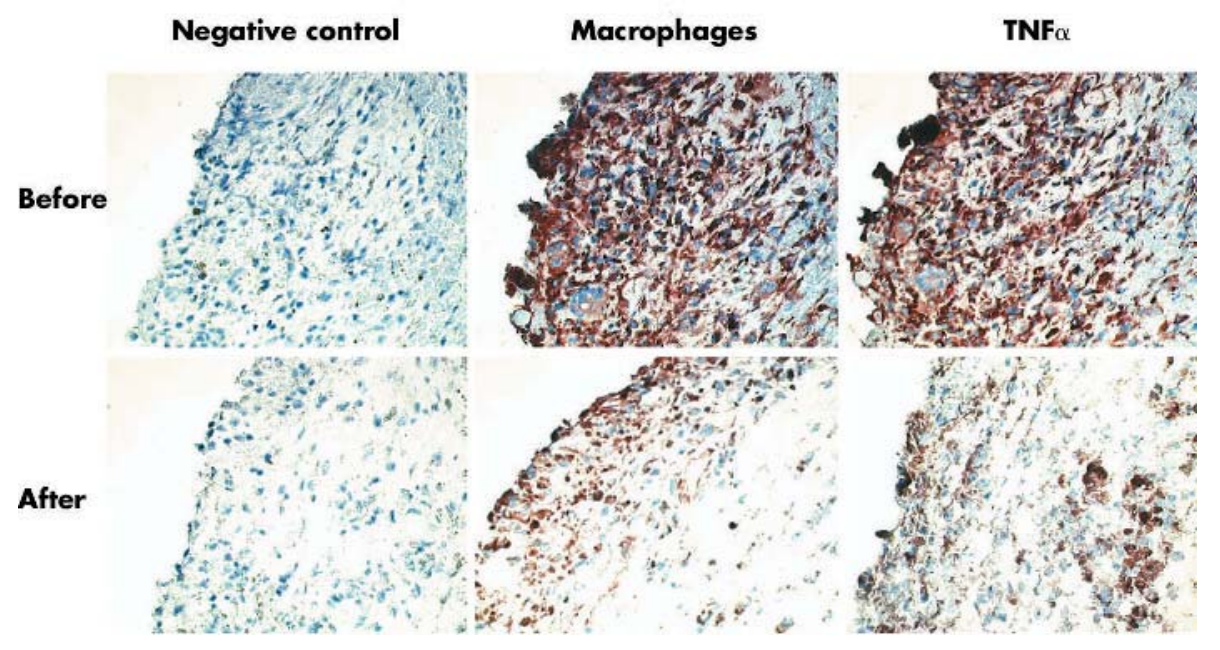

Figure 2 Pathological specimen of pigmented villonodular synovitis before and after 20 weeks of treatment with anti-TNF $\alpha$. Before treatment: classic histological features were seen, with pigment depositions and an impressive infiltrate, mainly consisting of macrophages with an abundant presence of $\mathrm{TNF} \alpha$, and immunohistochemical staining for macrophages and TNF $\alpha$ at baseline. After treatment: a dramatic reduction in cellularity, number of macrophages, estimated pigment, and TNF $\alpha$ after 20 weeks of treatment with anti-TNF $\alpha$ was seen. 
(RA), infliximab reduces the number of inflammatory cells in synovial tissue as soon as 48 hours after the start of treatment. ${ }^{10}$ In RA it has been demonstrated that there is a close relation between the magnitude of local inflammation and macrophages and their related cytokines. ${ }^{11}{ }^{12}$ Therefore, targeting macrophages and related cytokines could be important in other diseases such as PVNS where macrophages are predominant cells.

TNF $\alpha$ is believed to have a key role in the pathogenesis of RA. ${ }^{10}$ Because large amounts of TNF $\alpha$ were found in PVNS, we suggested that TNF $\alpha$ might also have a similar role in the pathogenesis of PVNS. Up to now PVNS has been considered to be a neoplastic-like disorder of the synovium, with synovitis as a secondary reaction in PVNS. ${ }^{24}$ Yudoh et al suggested that the pathological mechanism for growth of hypertrophic villi in PVNS is different from synovial growth in RA. ${ }^{4}$ Synovial hyperplasia in PVNS might be due to up regulation of synoviocyte proliferation as represented by activation of telomerase, which is evident in the majority of tumour cell lines. ${ }^{4}$ From this point of view it is not surprising that treatment with $\mathrm{TNF} \alpha$ blockade did not reduce the synovial tumour mass as measured by MRI. However a marked decrease in macrophages and $\mathrm{TNF} \alpha$ production might have stopped, or at least delayed, the destructive potency of this tumour in our patient.

In RA, TNF $\alpha$ blockade results in immediate clinical improvement and reduced macrophage infiltration in the synovium. ${ }^{10}$ In our patient disease control was only achieved after a few months, with persisting effusion of the knee during the first months of treatment, even with the markedly higher dose of infliximab $(5 \mathrm{mg} / \mathrm{kg})$ in comparison with the dose used in a previous synovial biopsy study in patients with RA ( $3 \mathrm{mg} / \mathrm{kg}$ ). This slower disease control might have been caused by the greater hyperplasia of the synovium observed in our patient.

To our knowledge, this is the first case of TNF $\alpha$ targeted treatment resulting in clinical and histological disease control in refractory PVNS. Debulking surgery, eventually followed by intra-articular ${ }^{90} \mathrm{Y}$ or radiation treatment, remains the first step for treatment of PVNS. Our report suggests that larger clinical studies with long term follow up are needed in order to determine the effects of infliximab on structural damage and possibly to delay significant surgery such as joint replacement in patients with PVNS with relapsing disease after open surgery and treatment with ${ }^{90} \mathrm{Y}$.

\section{Authors' affiliations}

E-J A Kroot, J M G W Wouters, Department of Rheumatology, St

Franciscus Hospital, Rotterdam, The Netherlands

M C Kraan, T J M Smeets, P P Tak, Division of Clinical Immunology and Rheumatology, Amsterdam Medical Centre, Amsterdam, The

Netherlands

M Maas, Department of Radiology, Amsterdam Medical Centre,

Amsterdam, The Netherlands

Correspondence to: Dr E-J A Kroot, Sint Franciscus Gasthuis, Department of Rheumatology, Kleiweg 500, 3045 PM Rotterdam, The Netherlands; ejankroot@yahoo.com

Accepted 3 July 2004

Published Online First 5 August 2004

\section{REFERENCES}

1 Jaffe HL, Lichtenstein L, Sutro CJ. Pigmented villonodularis synovitis: bursitis and tenosynovitis. Arch Pathol 1941;31:731-5.

2 Akgun I, Ogut T, Kesmezacar H, Dervisoglu S. Localized pigmented villonodular synovitis of the knee. Orthopedics 2003;26:1131-1.

3 Shabat S, Kollender Y, Merimsky O, Isakov J, Flusser G, Nyska M, et al. The use of surgery and yttrium 90 in the management of extensive and diffuse pigmented villonodular synovitis of large joints. Rheumatology (Oxford) 2002;41:1113-18.

4 Yudoh K, Matsuno H, Nezuka T, Kimura T. Different mechanisms of synovial hyperplasia in rheumatoid arthritis and pigmented villonodular synovitis: The role of telomerase activity in synovial proliferation. Arthritis Rheum 1999:42:669-77.

5 Dale K, Smith H-J, Paus AC, Refsum SB. Dynamic MR-imaging in the diagnosis of pigmented villonodular synovitis of the knee. Scand J Rheumatol 2000;29:336-9.

6 Flandry F, Hughston JC, McCann SB, Kurtz DM. Diagnostic features of diffuse pigmented villonodular synovitis of the knee. Clin Orthop 1994;298:212-20.

7 Yoshida W, Uzuki M, Kurose A, Yoshida M, Nishida J, Shimamura T, et al. Cell characterization of mononuclear and giant cells constituting pigmented villonodular synovitis. Hum Pathol 2003;34:65-73.

8 O'Keefe RJ, Rosier RN, Teot LA, Stewart JM, Hicks DG. Cytokine and matrix metalloproteinase expression in pigmented villonodular synovitis may mediate bone and cartilage destruction. lowa Orthop J 1998;18:26-34.

9 Kraan MC, Reece RJ, Smeets TJ, Veale DJ, Emery P, Tak PP. Comparison of synovial tissues from the knee joints and the small joints of rheumatoid arthritis patients: implications for pathogenesis and evaluation of treatment. Arthritis Rheum 2002;46:2034-8.

10 Smeets TJ, Kraan MC, van Loon ME, Tak PP. Tumor necrosis factor alpha blockade reduces the synovial cell infiltrate early after initiation of treatment, but apparently not by induction of apoptosis in synovial tissue. Arthritis Rheum 2003;48:2155-62.

11 Tak PP, Smeets TJ, Daha MR, Kluin PM, Meijers KA, Brand R, et al. Analysis of the synovial cell infiltrate in early rheumatoid synovial tissue in relation to local disease activity. Arthritis Rheum 1997;40:217-25.

12 Kraan MC, Versendaal H, Jonker M, Bresnihan B, Post WJ, + Hart BA, et al. Asymptomatic synovitis precedes clinically manifest arthritis. Arthritis Rheum 1998;41:1481-8. 